\title{
Article \\ Effect of Low-Energy Nitrogen Ion Implantation on Friction and Wear Properties of Ion-Plated TiC Coating
}

\author{
Zhongyu Dou ${ }^{1, *}$, Yinglu Guo ${ }^{1}$, Faguang Zhang ${ }^{2}$ and Dianxi Zhang ${ }^{1}$ \\ 1 College of Physics and Electronic Science, Anshun University, Anshun 561000, China; \\ gyl15772325021@163.com (Y.G.); xiwa_315@163.com (D.Z.) \\ 2 Refabrication, Guizhou Electromechanical Research and Design Institute, Guiyang 550025, China; \\ zhangfg89@163.com \\ * Correspondence: 2012620@asu.edu.com
}

\section{check for}

updates

Citation: Dou, Z.; Guo, Y.; Zhang, F.; Zhang, D. Effect of Low-Energy

Nitrogen Ion Implantation on Friction and Wear Properties of Ion-Plated TiC Coating. Coatings 2021, 11, 775 .

https://doi.org/10.3390/

coatings 11070775

Received: 21 May 2021

Accepted: 26 June 2021

Published: 29 June 2021

Publisher's Note: MDPI stays neutral with regard to jurisdictional claims in published maps and institutional affiliations.

Copyright: (c) 2021 by the authors. Licensee MDPI, Basel, Switzerland. This article is an open access article distributed under the terms and conditions of the Creative Commons Attribution (CC BY) license (https:// creativecommons.org/licenses/by/ $4.0 /)$.

\begin{abstract}
To further improve the performance of the coated tools, we investigated the effects of low-energy nitrogen ion implantation on surface structure and wear resistance for $\mathrm{TiC}$ coatings deposited by ion plating. In this experiment, an implantation energy of $40 \mathrm{keV}$ and a dose of $2 \times 10^{17}$ to $1 \times 10^{18}$ (ions $/ \mathrm{cm}^{2}$ ) were used to implant $\mathrm{N}$ ions into the TiC coatings. The results indicate that the surface roughness of the coating increases first and then decreases with the increase of ion implantation dose. After ion implantation, the surface of the coating will soften and reduce the hardness, and the production of TiN phase will gradually increase the hardness. Nitrogen ion implantation can reduce the friction coefficient of the TiC coating and improve the friction performance. In terms of wear resistance, the coating with an implant dose of $1 \times 10^{18}$ ions $/ \mathrm{cm}^{2}$ has the greatest improvement in wear resistance. Tribological analysis shows that the improvement in the performance of TiC coatings implanted with $\mathrm{N}$ ions is mainly due to the effect of the lubricating implanted layer. The implanted layer mainly exists in the form of amorphous $\mathrm{TiC}, \mathrm{TiN}$ phase, and $\mathrm{sp}^{2} \mathrm{C}-\mathrm{C}$ phase.
\end{abstract}

Keywords: $\mathrm{N}$ ion implantation; TiC coating; microstructure; friction coefficient; wear

\section{Introduction}

Hard alloy material is widely used in cutting tools, deep processing, and other fields because of its good hardness, strength, and elastic modulus. However, the requirements of some application environments can be demanding, which necessitates further improvement of the friction and wear performance of the tool surface. The use of tool coating treatments is an important method for improvement of comprehensive performance. Its pivotal role is to combine the features of the metal substrate and the hard coating, thereby maintaining the toughness of the metal substrate while adding hardness and other characteristics of the coating [1]. Many studies have reported coating preparations on tool surfaces because a coating with excellent performance can fully protect the tool and significantly reduce the wear degree of the tool [2-6]. At present, coatings prepared by the PVD (Physical Vapor Deposition) or CVD (Chemical Vapor Deposition) method are not enough for the use requirements, and the composite treatment of coatings are a good choice. Iram et al. improved the wear resistance of $\mathrm{AlCrN}$ coating by adding Mo or $\mathrm{V}$ elements [7]. Zhang et al. reported that laser substrate pretreatment improved the antiadhesive wear resistance of TiAlN coating on WC/CO substrate surface [8]. Li et al. reported inserting Ti layers to enhance the performance of TiAlSiN coated carbide tools [9]. Additionally, posttreatment of the coating surface is an effective method to further improve the performance of the tool. There are several ways to perform posttreatment of a coating surface, including nitriding [10], carburizing [11], heat treatment [12], and ion implantation [13]. Among these technical solutions, ion implantation has become one of the most preferred surface treatment methods. Research achievements in the regulation of alloys or nano films include the use of nitrogen or carbon atoms for modification by ion implantation technology 
as the nitrides or carbides formed have excellent wear and corrosion resistance [14-17]. Sharkeev et al. revealed the effect of $\mathrm{N}$ saturation and reported that high-dose $\mathrm{N}$ ion implantation significantly improved the wear resistance of TiN films deposited by physical vapor deposition [18]. Yang et al. reported that the improvement of friction and wear properties of TiN films implanted with $\mathrm{N}$ and Ti ions was due to the formation of nano-scale TiN grains in the thick amorphous layer [19]. Shum et al. reported that TiAlN coating after $\mathrm{C}$ ion implantation can greatly improve the wear resistance [20]. TiC film has high hardness, medium elastic modulus, and good oxidation resistance, and has been widely used in tool steels and coated tools. Some studies have shown that TiC films have lower friction coefficients and surface roughness than TiN and TiCN films, as well as higher oxidation resistance [21,22]. For coated tools used in high-speed cutting or dry machining, we need to further improve the surface properties of TiC films to maintain a low friction coefficient while improving its wear resistance. Revati et al. reported that the TiC film of DC (direct-current) magnetron sputtering with $600 \mathrm{keV} \cdot \mathrm{C}$ ion implantation improved the wear resistance, and the improvement of the properties was related to the amorphicity of the TiC phase [23]. Typically, the implanted ions diffuse from their Gaussian-type distribution into the surface to provide a relatively smooth gradient between the un-implanted and implanted regions. In addition to the shallow implanted zone near the surface, there are additional beneficial work-hardening effects in the deeper regions extending to depths of the order of a micrometer [24].

It is believed that injecting nitrogen $(\mathrm{N})$ or carbon $(\mathrm{C})$ into the TiC coating can improve the friction and wear properties of the $\mathrm{TiC}$ coating. However, the surface modification of coatings by nitrogen ion and ion implantation is not simple, largely due to complexities of the ion dose and energy. At present, there is no report on the effect of low-energy $\mathrm{N}$ ion implantation on $\mathrm{TiC}$ coatings. In this work, TiC coatings were prepared on the surface of the cemented carbide material by vacuum ion-plated technology, and the effect of different doses of low-energy nitrogen ion implantation on the on the microstructure, mechanical properties and friction and wear properties of $\mathrm{TiC}$ coatings were studied. The correlation of friction and wear was established by the changes in the microstructure and mechanical properties of TiC coatings implanted with $\mathrm{N}$ ions. The surface structure was studied using an X-ray diffractometer and atomic force microscope, and the mechanical properties were tested by nanoindentation.

\section{Materials and Methods}

The experimental substrate materials were $16 \mathrm{~mm} \times 16 \mathrm{~mm} \times 4.8 \mathrm{~mm}$ YG8 cemented carbide tools, purchased from Hunan Zhuzhou Diamond Alloy Tool Co., Ltd. (Zhuzhou, China) Initially, the tool surface was mechanically polished and ultrasonically cleaned with anhydrous ethanol. After drying, it was held in a vacuum chamber for preparation. For coating, the substrate was cleaned with $\mathrm{Ar}$ ion (99.999\%) to remove the surface oxides and other pollutants. The chamber was evacuated to $5 \times 10^{-3} \mathrm{~Pa}$, and the deposition temperature was $350^{\circ} \mathrm{C}$. High purity $\mathrm{Ti}(99.999 \%)$ and $\mathrm{C}_{2} \mathrm{H}_{2}$ were used for $\mathrm{TiC}$ coating, with a target current of $60 \mathrm{~A}$, a substrate negative bias of $-400 \mathrm{~V}$, and a deposition time of $150 \mathrm{~min}$. Implantation equipment was used for nitrogen ion implantation treatment for the coated specimens by a Kaufman gas ion source (Southwestern Institute of Physics, Chengdu, China). The $\mathrm{N}$ ion implantation, with an implantation dose range of $2 \times 10^{17}$ to $1 \times 10^{18}$ (ions $/ \mathrm{cm}^{2}$ ), was carried out with the cavity evacuated to $2 \times 10^{-3} \mathrm{~Pa}$ and an implantation energy of $40 \mathrm{keV}$, as presented in Table 1 . 
Table 1. The parameters of the ion implantation process.

\begin{tabular}{|c|c|c|c|}
\hline Sample & Dose (ions $/ \mathrm{cm}^{2}$ ) & $\begin{array}{c}\text { Implant Energy } \\
(\mathrm{keV})\end{array}$ & Implanted Ion \\
\hline S1 & 0 & 40 & Nitrogen \\
\hline $\mathrm{S} 2$ & $2 \times 10^{17}$ & 40 & Nitrogen \\
\hline S3 & $5 \times 10^{17}$ & 40 & Nitrogen \\
\hline S4 & $1 \times 10^{18}$ & 40 & Nitrogen \\
\hline
\end{tabular}

SRIM/TRIM (The stopping and range of ions in matter) software (2013) was used to simulate the ion concentration distribution of $\mathrm{N}$ ions with an energy of $40 \mathrm{keV}$ in the TiC coating [25]. An X-ray diffractometer (PANalytical X'Pert PRO, Almelo, Holland) was used to analyze the crystal structure of the coatings with a detection angle of $20^{\circ}-80^{\circ}$, a scanning speed of $10^{\circ} / \mathrm{min}$, and a step size of $0.013^{\circ} / \mathrm{s}$. The 3-dimensional morphology and surface roughness of the $\mathrm{TiC}$ coating were measured with an atomic force microscope (Bruker Dimension Icon AFM, Karlsruhe, Germany). A Nanoindenter (CSM UNHT, Shanghai, China) and friction and wear tester (Bruker UMT-2, Karlsruhe, Germany) were used to study the surface mechanical properties and friction and wear properties of the TiC coatings, and a laser 3-dimensional microscopic imaging system (OLYMPUS, Tokyo, Japan) was used to measure the wear cross-sectional area to judge the amount of wear. The friction method used a circular motion of $300 \mathrm{rpm} / \mathrm{min}$ for $30 \mathrm{~min}$, with a load of $5 \mathrm{~N}$ and a wear scar radius of $12 \mathrm{~mm}$. Dry friction was carried out with an $10 \mathrm{~mm} \mathrm{Al} \mathrm{O}_{3}$ ball (HRC95) at room temperature, and the surface of the wear scar was observed with a scanning electron microscope (ZIESS SUPRA40, Jena, Germany).

\section{Results}

\subsection{Ions Penetration Data}

Figure 1 shows the impurity profile simulated using TRIM software for nitrogen ions having an energy of $40 \mathrm{keV}$, where the red dots show the ion track. Ion bombardment causes the ejection of atoms or cluster, which then diffuse to the surface due to motion [26]. SRIM is commonly used for the calculation of overall stopping power and ion range. In this case, however, dynamic simulation (TRIM) was used for calculating the ion ranges of all ions employed in the simulation [25]. Figure 1a shows that, when the $40 \mathrm{keV}$ energy ion beam striked the TiC flims surface, it followed different trajectories. Finally, most of the nitrogen ions diffused into the flim surface at the depth of about $\sim 75 \mathrm{~nm}$, while a few of the $\mathrm{N}$ ions may have also reflected from the surface of the $\mathrm{TiC}$ flim at some angles. Figure $1 \mathrm{~b}$ shows the pattern of nitrogen ion distribution after implantation, from $170 \mathrm{~nm}$ in depth to the surface area of the TiC film. It was found that the implanted $\mathrm{N}$ ions exhibited a nearly Gaussian distribution and had a peak concentration at a depth of about $83 \mathrm{~nm}$ below the surface. The depth of the implanted zone (IZ) will increase with the implantation dose.
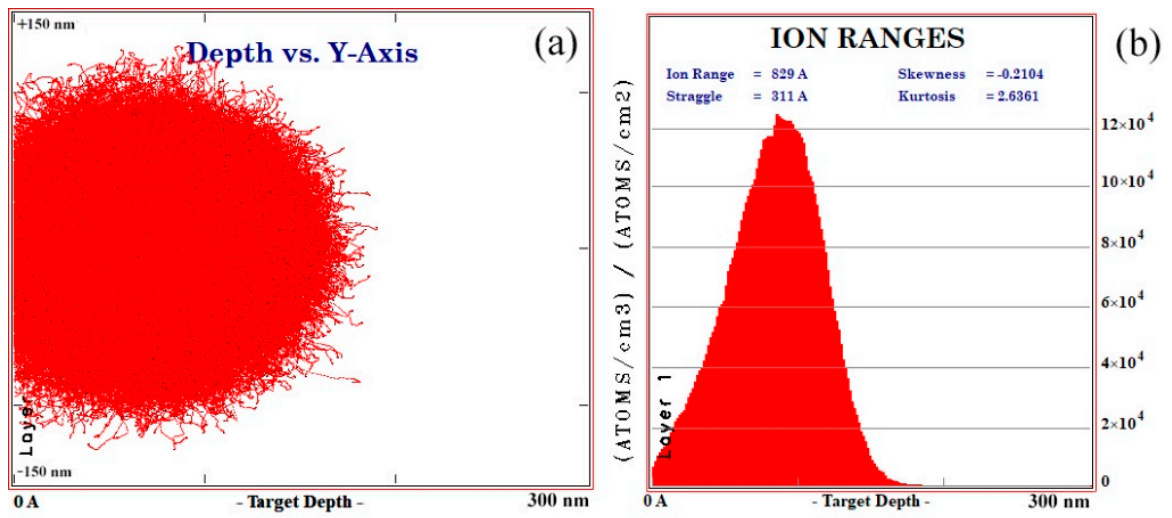

Figure 1. TRIM simulation for the (a) ion beam pattern, (b) ion distribution profile. 


\subsection{The Structure and Surface Morphology of the Coatings}

Researchers often use scanning electron microscope (SEM) to observe the microstructure of coating. The surface and cross section morphology of TiC coating in the deposition state are shown in Figure 2. The SEM pictures indicate that the coating had a homogeneous distribution of small grains and was free from crystal defects such as cracks. From Figure $2 b$, it can be seen that the thickness of the coating sample was about $6.5 \mu \mathrm{m}$.

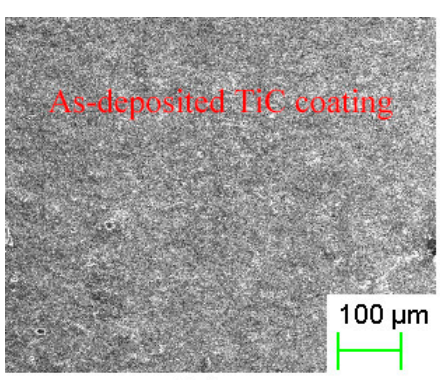

(a)

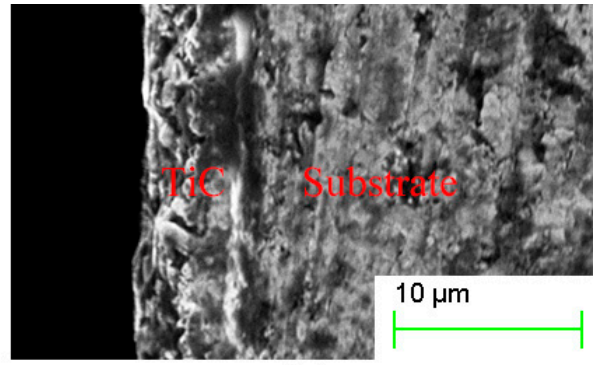

(b)

Figure 2. SEM micrograph showing the morphology of the as-deposited TiC thin film: (a) Surface (b) cross-section.

The X-ray Diffraction (XRD) results of $\mathrm{N}$ ion-implanted TiC coating with different implant doses are shown in Figure 3. We clearly see that, when the dose of $\mathrm{N}$ ion implantation was increased, the TiC diffraction peak shifted to a higher $2 \theta$ angle. A similar effect was observed by Singh et al., and they attributed it to the development of compressive stress on the surface of the nitride layer [26]. Another reason for this kind of shift may be due to the presence of light impurities, such as carbon and oxygen, in the sample [27]. The XRD analysis results of the implanted and un-implanted samples differed little when

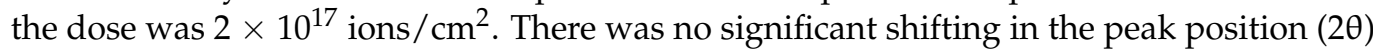
of diffraction peaks in the pattern, but variation in the peak intensity was clearly visible. When the implantation dose reached $5 \times 10^{17}$ ions $/ \mathrm{cm}^{2}$, the TiN diffraction peak appeared. As the implantation dose further increased, the diffraction peak intensity also increased. From the perspective of the constant characteristics of ion implantation, this result was due to the increase of $\mathrm{N}$ ions and the TiN phase [28]. In addition, we noticed the existence of $\mathrm{C}$ element in the coating, which was considered to be due to the existence of $\mathrm{sp}^{2}$ hybrid rich carbon in the TiC coating prepared by vacuum ion plating $[29,30]$.

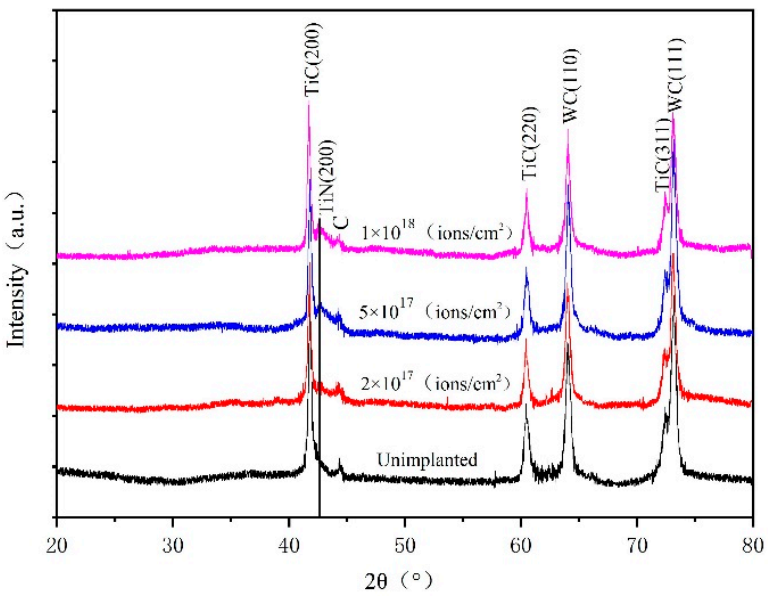

Figure 3. XRD patterns of TiC coatings implanted with different doses of $\mathrm{N}$ ion.

Ion implantation has been reported to be able to modify the surface morphologies and roughness of samples [31]. Surface roughness of the samples is subject to change by 
bombardment, which was observed by AFM (Figure 4). The changes of the average and root mean square (RMS) roughness of each sample with ion dose are presented in Table 2. As the ion implantation dose increased, the surface morphology of the coating changed significantly, with a notable growth in surface roughness. Ion implantation induced roughening of the crystalline surface that was mechanistically related to implantationinduced mass transfer, the generation of dangling-bonds, radiation-enhanced segregation, and diffusion. Nuclear energy loss in the ion implantation led to surface erosion by elastic collisions. Since the ion interaction is a stochastic process and sputtering events are spatially distributed in variable magnitudes, the surface is generally roughened during ion bombardment [23]. However, when the even larger dose of $1 \times 10^{18} \mathrm{ions} / \mathrm{cm}^{2}$ was applied, the RMS roughness dropped. The roughness decrease at the largest dose might be attributed to the sputtering, etching, and diffusion processes occurring at that high concentration.

(a)

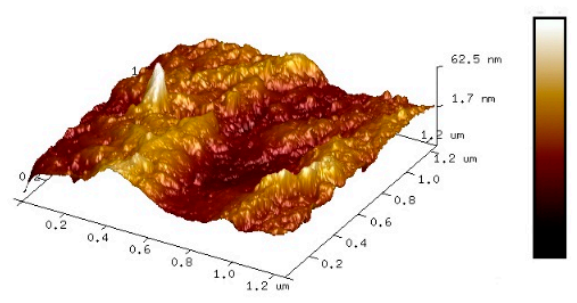

(c)

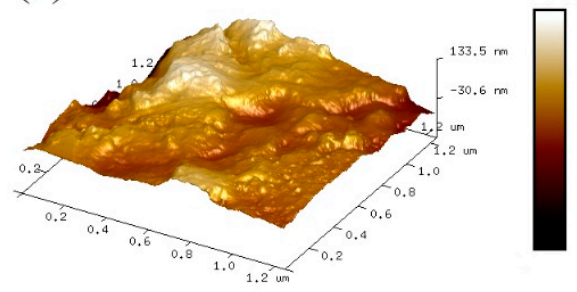

(b)

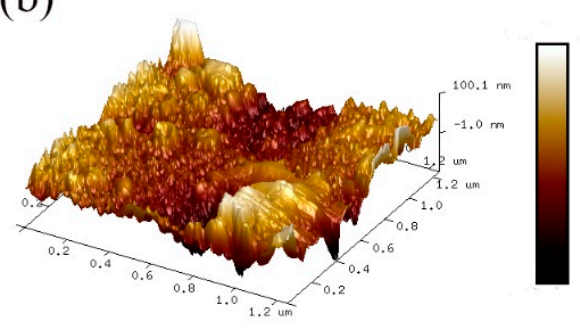

(d)

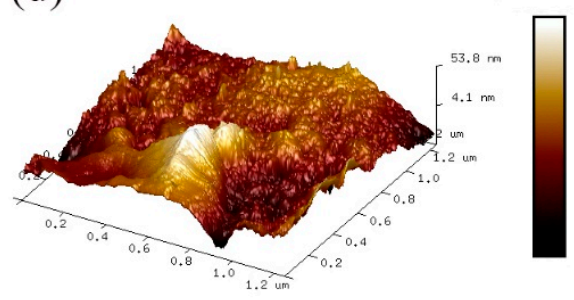

Figure 4. Three-dimensional AFM images of the samples: (a) Un-implanted; (b) implanted, dose $2 \times 10^{17}$ ions $/ \mathrm{cm}^{2}$; (c) implanted, dose $5 \times 10^{17}$ ions $/ \mathrm{cm}^{2}$; (d) implanted, dose $1 \times 10^{18}$ ions $/ \mathrm{cm}^{2}$.

Table 2. Roughness information.

\begin{tabular}{ccccc}
\hline Sample (\#) & Pristine & $\begin{array}{c}\mathbf{2} \times \mathbf{1 0}^{\mathbf{1 7}} \\
\left(\mathbf{i o n} / \mathbf{c m}^{\mathbf{2}}\right)\end{array}$ & $\begin{array}{c}\mathbf{5} \times \mathbf{1 0}^{\mathbf{1 7}} \\
\left(\mathbf{i o n} / \mathbf{c m}^{\mathbf{2}}\right)\end{array}$ & $\begin{array}{c}\mathbf{1} \times \mathbf{1 0}^{\mathbf{1 8}} \\
\left.\mathbf{( i o n} / \mathbf{c m}^{\mathbf{2}}\right)\end{array}$ \\
\hline RMS roughness $(\mathrm{nm})$ & 12.8 & 27.6 & 38.4 & 12.3 \\
Average roughness $(\mathrm{nm})$ & 9.59 & 21.6 & 26.9 & 9.96 \\
\hline
\end{tabular}

\subsection{Hardness Measurement}

An ultra-micro hardness test was carried out to observe the influence of $\mathrm{N}$ ion implantation on the mechanical properties of the implanted zone (IZ). The nanoindentation test used a maximum load of $1 \mathrm{mN}$ and a loading and unloading rate of $0.3 \mathrm{mN} / \mathrm{min}$. The Oliver and Pharr continuous stiffness method was used to analyze the indentation size. Based on these measurements, the hardness value was calculated. Different samples of results obtained by depth-sensing indentation test are shown in Figure 5. We found that the maximum indentation depth was higher for the ion-implanted films than for virgin TiC films, which suggests softening of all the coatings after the treatment. Many scholars have reported similar phenomena [23,32-34]. It is believed that this is due to defects and possible amorphization caused by ion bombardment. The implantation-affected zone (IAZ) contains the volume of material affected by ion bombardment and is located between the substrate and the implanted (nitrogen-rich) layer. The characteristics of this zone signifi- 
cantly affect the mechanical properties of the implanted layer and the amorphization of the top layers of similar PVD, TiC, or TiN coatings when implanted by light elements in this range of energy. Table 3 shows the average hardness and Young's modulus of each sample. The average values of hardness and Young's modulus in pristine TiC coating were found to be 20.586 and $231.9 \mathrm{Gpa}$. As the ion implantation dose increased, the hardness and Young's modulus increased. It is well known that elastic modulus scales with its crystalline fraction, so the increase in surface elastic modulus after irradiation can be related to the change in crystallinity [35]. Initially, the increase in surface microhardness is attributable to the formation of additional TiN phases in nitrogen ion-irradiated TiC coatings. This increasing trend in surface hardness value continued at higher fluences ranging from $5 \times 10^{17}$ to $1 \times 10^{18}$ ions $/ \mathrm{cm}^{2}$. The increase in surface hardness at higher fluences is mainly attributed to the formation of ion induced points defects [36]. The concentration of point defects increased by increasing ion fluence and, correspondingly, an increase in surface hardness was observed. The decrease in crystallite size at higher fluence may also be considered as the possible factors responsible for the increase in microhardness at higher fluences [37].

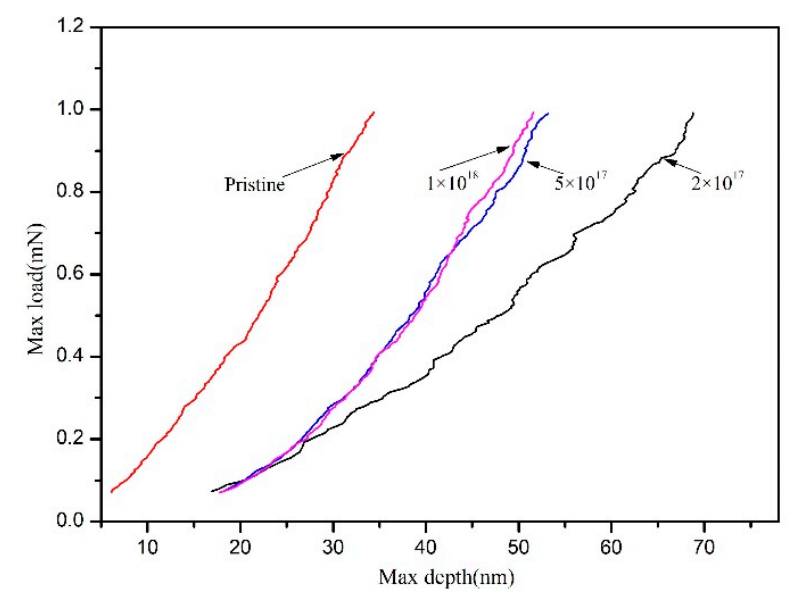

Figure 5. Depth-sensing indentation test results of different samples.

Table 3. Hardness and Young's modulus information.

\begin{tabular}{ccccc}
\hline Sample (\#) & Pristine & $\begin{array}{c}\mathbf{2} \times \mathbf{1 0}^{\mathbf{1 7}} \\
\left(\mathbf{i o n} / \mathbf{c m}^{\mathbf{2}}\right)\end{array}$ & $\begin{array}{c}\mathbf{5} \times \mathbf{1 0}^{\mathbf{1 7}} \\
\left(\mathbf{i o n} / \mathbf{c m}^{\mathbf{2}}\right)\end{array}$ & $\begin{array}{c}\mathbf{1} \times \mathbf{1 0}^{\mathbf{1 8}} \\
\left(\mathbf{i o n} / \mathbf{c m}^{\mathbf{2}}\right)\end{array}$ \\
\hline $\begin{array}{l}\text { Average hardness (GPa) } \\
\text { Young's modulus (GPa) }\end{array}$ & 20.586 & 4.332 & 6.758 & 7.265 \\
\hline
\end{tabular}

\subsection{Friction and Wear Performance}

The friction coefficient and the amount of wear are important indicators for friction and wear performance. Figure 6 shows the friction coefficient curve of the samples under different implantation doses. The average friction coefficient of the surface coatings of all samples with differing implantation doses reached about 0.6 after different sliding distances. The period from the onset of friction to the sharp rise of the friction coefficient was the effective period of the sample surface modification layer. The friction coefficient of the unimplanted sample coating increased sharply after sliding for $30 \mathrm{~m}$ and tended to stabilize with a final friction coefficient of about 0.6. In the sample with a dose of $2 \times 10^{17}$ ions $/ \mathrm{cm}^{2}$, the friction coefficient began to increase after the sliding distance increased to $55 \mathrm{~m}$ and stabilized at about 0.6 after sliding for $90 \mathrm{~m}$. In the sample with a dose of $5 \times 10^{17} \mathrm{ions} / \mathrm{cm}^{2}$, the sliding distance reached $110 \mathrm{~m}$ before the coefficient increased to about 0.6 . In the sample with the highest injection dose of $1 \times 10^{18}$ ions $/ \mathrm{cm}^{2}$, the friction coefficient of the coating remained stable within a sliding distance of $260 \mathrm{~m}$, with an average friction coefficient of 0.235 . In this study, the posttreatment of $\mathrm{N}$ ion implantation process on the 
TiC coatings trended toward a decrease of the friction coefficient, which may have been due to the soft surface layer formed on the surface. This softening reduced the shear stress at the contact point, thereby reducing the friction coefficient, making the IZ layer act as a solid lubricant [38]. However, solid lubricants cannot heal themselves and will gradually disappear with wear [39]. Under the condition of high-dose $\mathrm{N}$ ion implantation, the surface modification layer forms a composite structure mainly composed of TiN/TiC phase and mixes with oxides, which acts as self-lubricating during the friction process. This has a positive effect on the performance of the friction coefficient.

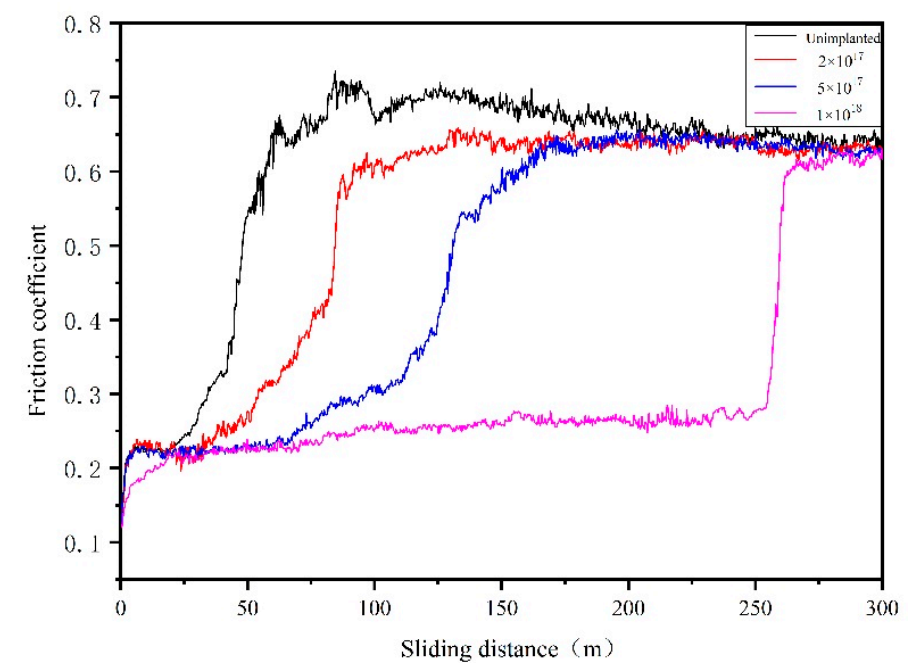

Figure 6. Variation curve of friction coefficient of different samples.

The wear resistance of the coating can be measured by the sliding distance or the amount of wear under dry friction, and the reduction of wear directly indicates wear resistance or improvement in the anti-wear ability of the sample. Figure 7 shows the cross-sectional areas of the coating wear scars for different implant doses after $30 \mathrm{~min}$ of the friction and wear test. The wear amount of the sample coatings implanted with $\mathrm{N}$ ions was lower than that of the un-implanted TiC coatings. When the $\mathrm{N}$ ion implantation dose increased to $1 \times 10^{18}$ ions $/ \mathrm{cm}^{2}$, the alloy had the greatest increase in wear resistance, with the best anti-wear effect among all samples, consistent with the friction coefficient results. The wear morphology of each sample observed by SEM and three-dimensional micrographs is shown in Figure 8. The TiC coatings with a high dose of $\mathrm{N}$ implantation generally showed smoother and more uniform wear, with a decrease in the width of wear scar. In addition, the observed phenomena, such as peeling pits, particle fragments, and slight plastic deformation, indicate that abrasive wear was the main form of wear after coating failure.

The softening of the IZ layer and production of the TiN phase can explain the decrease in friction coefficient at different doses. The wear behavior can be explained by the model of the grain-mixed thin, soft layer, which describes the friction coefficient $\mu$ as the ratio of the surface shear strength (S) to the hardness, thereby explaining the variation of the friction coefficient with the ion implantation dose $[33,39]$. When the implantation dose was $1 \times 10^{18}$ ions $/ \mathrm{cm}^{2}$, the IZ layer increased with the increase of the dose. The $\mu$ decreased with the increase of the dose, while the implantation effect was optimal at this time, so a very low friction area was observed within $260 \mathrm{~m}$. The wear trajectory in Figure 7 shows that, after the implantation layer fell off, the wear debris was deposited in the wear scar or the edge of the wear scar. During the friction process, the debris deposited in the wear scar was deformed and debonded, and the debonded particles were transferred and redeposited in the wear track. When deposited in the form of a continuous layer, it can also act as a barrier between the friction ball and the surface of the sample, thereby reducing the wear rate. Perhaps due to this effect, the coating with a dose of $1 \times 10^{18}$ ions $/ \mathrm{cm}^{2}$ had the 
most wear resistance. In addition, the presence of amorphous carbon in the TiC coating prepared by ion plating is also an important factor affecting performance. The $\mathrm{sp}^{2} \mathrm{C}-\mathrm{C}$ phase with graphite structure can have an excellent lubricating effect during the friction process, which has been confirmed [24,40]. In conclusion, the improvement of friction and wear performance of $\mathrm{TiC}$ coating by $\mathrm{N}$ ion implantation is due to the comprehensive effect of many effects.

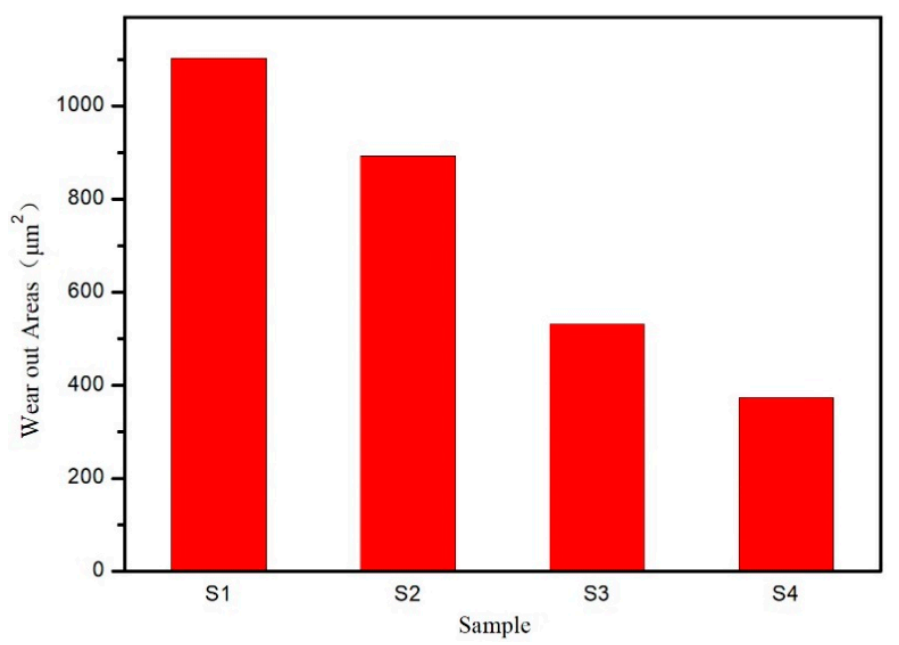

Figure 7. Cross-sectional area of coating wear scars with different implant doses.

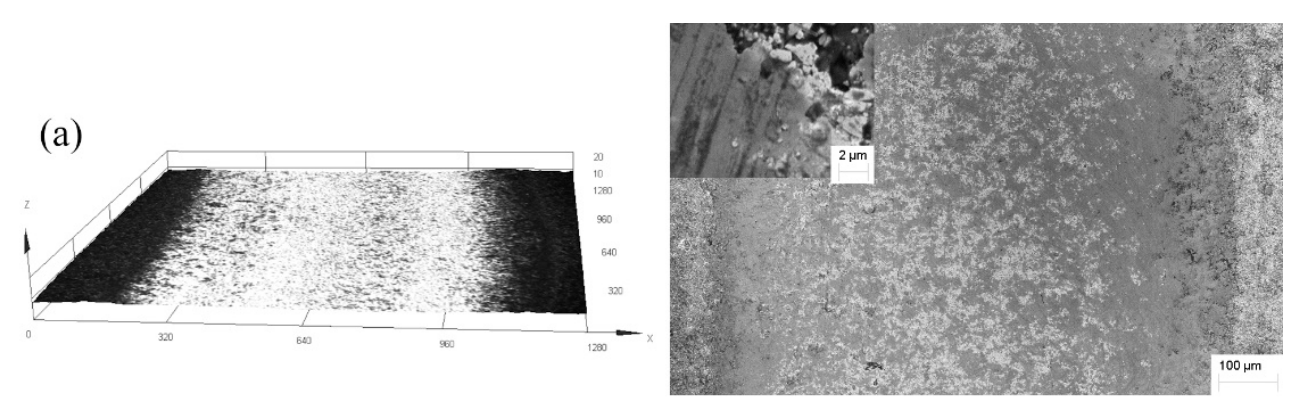

(b)
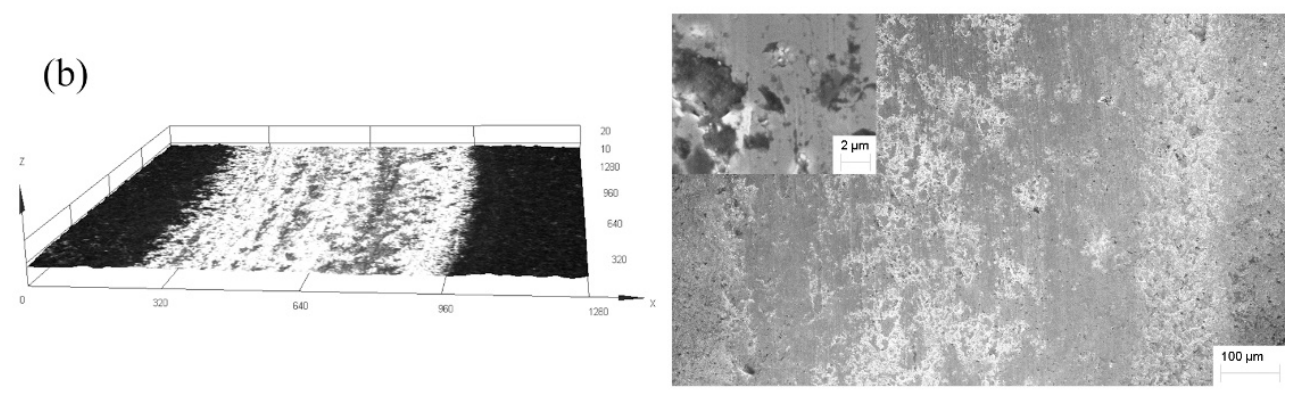

(c)
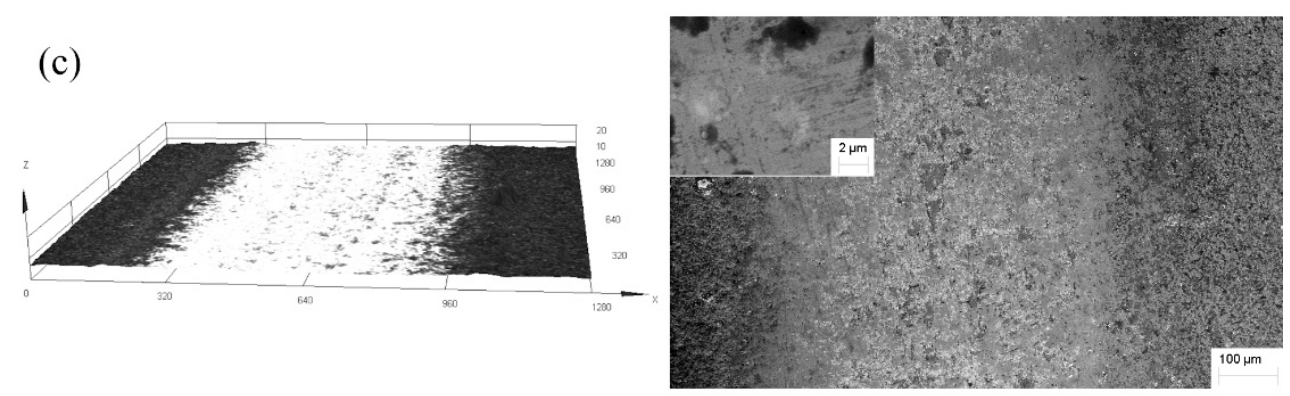

Figure 8. Cont. 
(d)

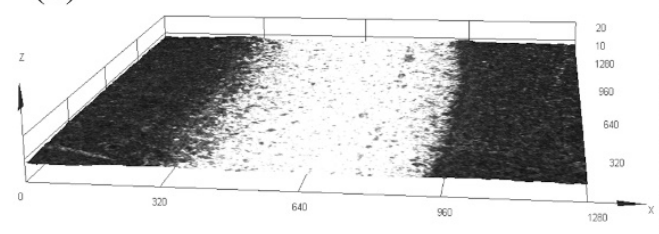

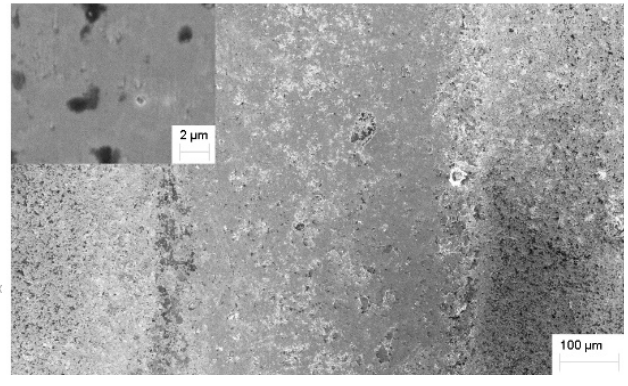

Figure 8. SEM and 3-dimensional micrographs show the wear morphology of the samples. (a) sample 1, Pristine (b) sample $2,2 \times 10^{17}$ (c) sample 3, $5 \times 10^{17}$ (d) sample $4,1 \times 10^{18}$.

\section{Conclusions}

The friction and wear properties of $\mathrm{TiC}$ coating post-treated with low-energy $\mathrm{N}$ ion implantation were studied. The results showed that the friction coefficient and wear rate of the $\mathrm{TiC}$ coating modified by $\mathrm{N}$ ion implantation were improved. Under $1 \times 10^{18}$ ions $/ \mathrm{cm}^{2}$ implantation dose, the improvement of the wear resistance of the coating was the greatest. In the first stage of wear, the friction coefficient was 0.235 , and it remained stable within $260 \mathrm{~m}$. XRD, AFM, and nano-hardness tests showed that the surface roughness of the coating increased first and then decreased with the increase of ion flux. The hardness of the modified surface coating decreased, but further increases of ion fluences from $5 \times 10^{17}$ to $1 \times 10^{18}$ ions $/ \mathrm{cm}^{2}$ improved the hardness of the modified layer, which is mainly attributed to the formation of point defects and TiN phase. From the worn surface morphology, it can be concluded that abrasive wear is the main form of wear after $\mathrm{N}$ ion implantation. The mechanical and tribological properties of TiC coating can be controlled by the dose of $\mathrm{N}$ ion implantation, which is of great significance to the industrial application of TiC coating.

Author Contributions: Conceptualization, Z.D. and D.Z.; methodology, F.Z.; software, Y.G.; validation, Z.D., Y.G., and F.Z.; formal analysis, Y.G.; investigation, D.Z.; resources, F.Z.; data curation, Z.D.; writing—original draft preparation, Z.D.; writing—review and editing, D.Z.; visualization, Y.G.; project administration, Z.D.; funding acquisition, Z.D. All authors have read and agreed to the published version of the manuscript.

Funding: This research was funded by the Youth Growth Project of The Education Department of Guizhou Province (2017281, 2020134), the Key Laboratory of Materials Simulation and Computing of Anshun University (Asxyxkpt201803) and National Undergraduate Innovation and Entrepreneurship Training Program of China (202010667017).

Institutional Review Board Statement: Not applicable.

Informed Consent Statement: Not applicable.

Data Availability Statement: No new data were created or analyzed in this study. Data sharing is not applicable to this article.

Acknowledgments: The author would like to thank the Mechanical and Electrical Research and Design Institute of Guizhou Province for providing the equipment and technical support. The Youth Growth Project of The Education Department of Guizhou Province (2017281,2020134), the Key Laboratory of Materials Simulation and Computing of Anshun University (Asxyxkpt201803) and National Undergraduate Innovation and Entrepreneurship Training Program of China (202010667017).

Conflicts of Interest: The authors declare no conflict of interest.

\section{References}

1. Zhu, S.; Hu, Y.; Zhang, X.; Zou, Y.; Ahmad, T.; Zhang, W.; Tang, F.; Liang, T. Experimental investigation on ultrasonic shot peening of WC-Co alloy. Mater. Manuf. Process. 2020, 35, 1576-1583. [CrossRef]

2. Tang, Y.; Li, Y.S.; Yang, Q.; Hirose, A. Deposition and characterization of diamond coatings on WC-Co cutting tools with W/Al interlayer. Diam. Relat. Mater. 2009, 19, 496-499. [CrossRef] 
3. Malarvannan, R.R.R.; Moorthy, T.V.; Ravi, S. Improvement of wear performance of high speed steel tool using physical vapour deposition coating process. Appl. Mech. Mater. 2015, 4123, 391-395. [CrossRef]

4. Adaskin, A.M.; Butrim, V.N.; Vereshchaka, A.S. Wear resistance of a coated hard-alloy tool in the machining of high-temperature chromium alloys. Russ. Eng. Res. 2016, 36, 867-871. [CrossRef]

5. Chang, Y.-Y.; Chang, H.; Jhao, L.-J.; Chuang, C.-C. Tribological and mechanical properties of multilayered TiVN/TiSiN coatings synthesized by cathodic arc evaporation. Surf. Coat. Technol. 2018, 350, 1071-1079. [CrossRef]

6. Yasuoka, M.; Wang, P.; Murakami, R. Comparison of the mechanical performance of cutting tools coated by either a TiC ${ }_{x} \mathrm{~N}_{1-x}$ single-layer or a TiC/ $\mathrm{TiC}_{0.5} \mathrm{~N}_{0.5} / \mathrm{TiN}$ multilayer using the hollow cathode discharge ion plating method. Surf. Coat. Technol. 2011, 206, 2168-2172. [CrossRef]

7. Iram, S.; Cai, F.; Wang, J.; Zhang, J.; Liang, J.; Ahmad, F.; Zhang, S. Effect of Addition of Mo or V on the structure and cutting performance of AlCrN-based coatings. Coatings 2020, 10, 298. [CrossRef]

8. Zhang, K.; Deng, J.; Meng, R.; Lei, S.; Yu, X. Influence of laser substrate pretreatment on anti-adhesive wear properties of WC/Co-based TiAlN coatings against AISI 316 stainless steel. Int. J. Refract. Met. Hard Mater. 2016, 57, 101-114. [CrossRef]

9. Li, G.; Li, L.; Han, M.; Luo, S.; Jin, J.; Wang, L.; Gu, J.; Miao, H. The performance of TiAlSiN coated cemented carbide tools enhanced by inserting Ti interlayers. Metals 2019, 9, 918. [CrossRef]

10. Krzysztof, S.; Jerzy, M.; Łukasz, M.; Małgorzata, P.; Michał, T.; Oleh, T.; Iryna, P.; Tadeusz, W. Effect of nitriding conditions of Ti6Al7Nb on microstructure of TiN surface layer. J. Alloy. Compd. 2020, 845, 156320.

11. Yanfeng, W.; Zhengxian, L.; Wei, L.; Jihong, D.; Shouchang, J.; Changwei, Z. Effect of substrate pre-carburizing on properties of TiN (Ti) hard coatings deposited on Ti-6Al-4V alloy. Rare Met. Mater. Eng. 2018, 47, 3295-3300. [CrossRef]

12. Song, Y.; Fu, B.; Dong, T.; Li, G.; Wang, F.; Zhao, X.; Liu, J. Effect of vacuum annealing treatment on dry sliding wear behavior of TiC/Ti-1100-0.5Nb composite under different operating temperatures. Mater. Today Commun. 2020, 23, 101136. [CrossRef]

13. Ward, L.P.; Purushotham, K.P.; Manory, R.R. MEVVA ion implantation of TiCN coatings; structural and tribological properties. Nuclear Inst. Methods Phys. Res. B 2019, 449, 40-48. [CrossRef]

14. Vlcak, P.; Cerny, F.; Drahokoupil, J.; Sepitka, J.; Tolde, Z. The microstructure and surface hardness of Ti6Al4V alloy implanted with nitrogen ions at an elevated temperature. J. Alloy. Compd. 2015, 620, 48-54. [CrossRef]

15. Ying, Z.; Man, W.S.; Man, W.H.; Shuilin, W.; Tao, H.; Kelvin, Y.W.K.; Chu, P.K. Effects of carbon and nitrogen plasma immersion ion implantation on in vitro and in vivo biocompatibility of titanium alloy. ACS Appl. Mater. Interfaces 2013, 5, 1510-1516.

16. Dai, J.; Liu, Z.; Yu, B.; Ruan, Q.; Chu, P.K. Effects of Ti, Ni, and dual Ti/Ni plasma immersion ion implantation on the corrosion and wear properties of magnesium alloy. Coatings 2020, 10, 313. [CrossRef]

17. Sharma, P.; Dhawan, A.; Sharma, S.K. Influence of nitrogen ion implantation on corrosion behavior of Zr55Cu30Ni5Al10 amorphous alloy. J. Non-Cryst. Solids 2019, 511, 186-193. [CrossRef]

18. Sharkeev, Y.P.; Bull, S.J.; Perry, A.J.; Klingenberg, M.L.; Fortuna, S.; Michler, M.; Manory, R.R.; Shulepov, I.A. On high dose nitrogen implantation of PVD titanium nitride. Surf. Coat. Technol. 2005, 2000, 5915-5920. [CrossRef]

19. Yang, J.H.; Cheng, M.F.; Luo, X.D.; Zhang, T.H. Surface properties and microstructure of implanted TiN films using MEVVA ion source. Mater. Sci. Eng. A 2006, 445, 558-562. [CrossRef]

20. PShum, W.; Zhou, Z.F.; Li, K.Y. A Study of the structural, mechanical and tribological properties of Ti-Al-N coatings post-treated by carbon implantation. Adv. Mater. Res. 2009, 844, 7-12.

21. Cheng, Y.; Zheng, Y.F. Characterization of TiN, TiC and TiCN coatings on Ti-50.6 at.\% Ni alloy deposited by PIII and deposition technique. Surf. Coat. Technol. 2006, 201, 4909-4912. [CrossRef]

22. Fang, T.-H.; Jian, S.-R.; Chuu, D.-S. Nanomechanical properties of TiC, TiN and TiCN thin films using scanning probe microscopy and nanoindentation. Appl. Surf. Sci. 2004, 228, 365-372. [CrossRef]

23. Rani, R.; Kumar, N.; Kumar, D.D.; Panda, K.; Srivastava, S.K.; Dash, S.; Tyagi, A.K. Improvement in wear resistance of C + ion implanted DC magnetron sputtered TiC film. Tribol. Int. 2016, 104, 121-130. [CrossRef]

24. Shum, P.W.; Xu, Y.F.; Zhou, Z.F.; Cheng, W.L.; Li, K.Y. Study of TiAlSiN coatings post-treated with $\mathrm{N}$ and $\mathrm{C}+\mathrm{N}$ ion implantations. Part 2: The tribological analysis. Wear 2012, 274, 274-280. [CrossRef]

25. Ziegler, J.F.; Ziegler, M.D.; Biersack, J.P. SRIM-The stopping and range of ions in matter (2010). Nucl. Inst. Methods Phys. Res. B 2010, 268, 1818-1823. [CrossRef]

26. Singh, O.; Malik, H.K.; Dahiya, R.P.; Kulriya, P.K. Tuning of mechanical and structural properties of $20 \mathrm{MC} 5$ steel using N ion implantation and subsequent annealing. J. Alloy. Compd. 2017, 710, 253-259. [CrossRef]

27. Solati, E.; Dorranian, D. Investigation of the structure and properties of nanoscale grain-size $\beta$-tantalum thin films. Mol. Cryst. Liq. Cryst. 2013, 571, 67-76. [CrossRef]

28. Alipour, R.; Khani, A.A.; Mohammadi, R.; Rostami, S. The effect of formation of titanium nitride thin film on surface characteristics of titanium by nitrogen ion implantation. J. Chem. Res. 2016, 40, 12-15. [CrossRef]

29. Yu, X.; Shanhua, C.; Zhaoyuan, N.; Mingrong, S.; Qian, X. The influence of different deposition gases on the preparation of TiC films by multi-arc method. Funct. Mater. 2000, 31, 16-18.

30. Ye, Y.; Wang, Y.; Chen, H.; Li, J.; Yao, Y.; Wang, C. Doping carbon to improve the tribological performance of CrN coatings in seawater. Tribol. Int. 2015, 90, 362-371. [CrossRef]

31. Chao, Y.; Qunfeng, Z.; Wanjun, H.; Jianing, Z. Enhanced surface hardness and tribocorrosion performance of $60 \mathrm{NiTi}$ by boron ion implantation and post-annealing. Tribol. Int. 2021, 155, 106816. 
32. Narojczyk, J.; Morozow, D. Modification of TiN coatings by ion implantation. Acta Mech. Et Autom. 2017, 11, 190-193. [CrossRef]

33. Purushotham, K.P.; Ward, L.P.; Brack, N.; Pigram, P.J.; Evans, P.; Noorman, H.; Manory, R.R. Tribological studies of Zr-implanted PVD TiN coatings deposited on stainless steel substrates. Wear 2003, 254, 589-596. [CrossRef]

34. Martínez-Martínez, D.; López-Cartes, C.; Fernández, A.; Sánchez-López, J.C. Influence of the microstructure on the mechanical and tribological behavior of TiC/a-C nanocomposite coatings. Thin Solid Film. 2008, 517, 1662-1671. [CrossRef]

35. Fasce, L.; Cura, J.; del Grosso, M.; Bermúdez, G.G.; Frontini, P. Effect of nitrogen ion irradiation on the nano-tribological and surface mechanical properties of ultra-high molecular weight polyethylene. Surf. Coat. Technol. 2010, 204, 3887-3894. [CrossRef]

36. Mahmood, K.; Bashir, S.; Akram, M.; Hayat, A.; Rafique, M.S.; Mahmood, A. Surface, structural, electrical and mechanical modifications of pulsed laser deposited $\mathrm{ZrN}$ thin films by implantation of $\mathrm{MeV}$ carbon ions. Nucl. Instrum. Methods Phys. Res. Sect. B Beam Interact. Mater. At. 2019, 448, 61-69. [CrossRef]

37. Ahmad, S.; Bashir, S.; Ali, N.; Yousaf, D.; Naeem, A.; Ahmad, R.; Khlaeeq-ur-Rahman, M. Effect of ion irradiation on the surface, structural and mechanical properties of brass. Nucl. Inst. Methods Phys. Res. B 2014, 325, 5-10. [CrossRef]

38. Kenneth, H. A concept for friction mechanisms of coated surfaces. Elsevier 1992, 56, 1-10.

39. Ludema, K. Mechanical wear prediction and prevention. Wear 1995, 184, 215-216. [CrossRef]

40. Zhang, H.S.; Endrino, J.L.; Anders, A. Comparative surface and nano-Tribological characteristics of nanocomposite diamondLike carbon thin films doped by silver. Appl. Surf. Sci. 2008, 255, 2551-2556. [CrossRef] 